\title{
LANDASAN ILMU PENGETAHUAN DAN TEKNOLOGI DALAM PENGEMBANGAN KURIKULUM PENDIDIKAN AGAMA ISLAM
}

\author{
Saridudin \\ Puslitbang Pendidikan Agama dan Keagamaan \\ Badan Litbang dan Diklat Kementerian Agama RI \\ dudinsaridudin@gmail.com
}

\begin{abstract}
Education is a conscious effort to prepare students through guidance, instruction, and training, as well as to equip students with the knowledge to play their role in the future. While technology is the application of scientific knowledge and other sciences to solve a practical problem. Thus science and technology can not be separated. Science and technology develop rapidly at the speed of the development of society. Science and technology have a reciprocal relationship with education and curriculum. Education and curriculum must be able to respond to the development of science and technology because education is an effort to prepare students for a better future. Curriculum development of all subjects including Islamic education should be based on the development of science and technology. The development of science and technology directly implicates curriculum development which includes objectives, materials, methods, and evaluation. Technology has an important role in the development of the Islamic education curriculum because Islamic education material should be kept up to date with the conditions and needs of the student. Islamic education learning should always be contextual with the real-life of the student so that its existence is always present and become the needs for the student.
\end{abstract}

Keywords: Science and technology, curriculum development, Islamic education

\begin{abstract}
Abstrak
Pendidikan adalah usaha sadar untuk menyiapkan peserta didik melalui kegiatan bimbingan, pengajaran dan atau latihan, serta membekali anak didik dengan ilmu pengetahuan guna perannya di masa mendatang. Sementara itu teknologi adalah aplikasi dari ilmu pengetahuan ilmiah dan ilmu-ilmu lainnya untuk memecahkan masalah-maslaah praktis. Dengan demikian Ilmu dan teknologi tidak bisa dipisahkan. Ilmu pengetahuan dan teknologi berkembang teramat pesat seiring lajunya perkembangan masyarakat. Ilmu pengetahuan dan teknologi mempunyai hubungan timbalbalik dengan pendidikan dan kurikulum. Pendidikan dan kurikulum harus mampu merespon perkembangan Ilmu Pengetahuan dan Teknologi yang begitu cepat, karena pendidikan merupakan upaya menyiapkan peserta didik menghadapi masa depan yang lebih baik. Pengembangan kurikulum semua mata pelajaran termasuk di dalamnya Pendidikan Agama Islam haruslah berlandaskan pada perkembangan ilmu pengetahuan dan teknologi. Perkembangan ilmu pengetahuan dan teknologi secara langsung berimplikasi terhadap pengembangan kurikulum yang di dalamnya mencakup tujuan, materi, metode dan evaluasi. Teknologi memiliki peranan penting dalam pengembangan kurikulum Pendidikan Agama Islam karena materi Pendidikan Agama Islam harus selalu up to date dengan kondisi dan kebutuhan peserta didik. Pembelajaran Pendidikan Agama Islam harus selalu kontekstual dengan kehidupan nyata peserta didik agar keberadaannya selalu hadir dan menjadi kebutuhan peserta didik.
\end{abstract}


Kata Kunci : Ilmu Pengetahuan dan Teknologi, Pengembangan Kurikulum, Pendidikan Agama Islam (PAI)

\section{A. Pendahuluan}

Ilmu pengetahuan adalah seperangkat pengetahuan yang disusun secara sistematis yang dihasilkan melalui riset atau penelitian. Sedangkan teknologi adalah aplikasi dari ilmu pengetahuan untuk memecahkan masalah-masalah praktis dalam kehidupan. Ilmu dan teknologi tidak bisa dipisahkan. Sejak abad pertengahan ilmu pengetahuan telah berkembang dengan pesat. Perkembangan ilmu pengetahuan pada masa kini banyak didasari oleh penemuan dan hasil pemikiran para filsuf purba seperti Plato, Socrates, Aristoteles, John Dewey, Archimides, dan lain-lain.

Pada awalnya, ilmu pengetahuan dan teknologi yang dimiliki manusia masih relatif sederhana, namun sejak abad pertengahan mengalami perkembangan yang pesat. Seiring dengan perkembangan pemikiran manusia, dewasa ini banyak dihasilkan temuan-temuan baru dalam berbagai bidang kehidupan manusia seperti kehidupan sosial, ekonomi, budaya, politik, dan kehidupan lainnya.

Ilmu pengetahuan dan teknologi mempunyai hubungan timbal-balik dengan pendidikan dan kurikulum. Industri dengan teknologi maju memproduksi berbagai macam alat-alat dan bahan yang secara langsung atau tidak langsung dibutuhkan dalam pendidikan dan sekaligus menuntut sumber daya manusia yang handal untuk mengaplikasikannya. Kegiatan pendidikan membutuhkan dukungan dari penggunaan alat-alat hasil industri seperti televisi, radio, video, komputer, dan peralatan lainnya. Penggunaan alat-alat yang dibutuhkan untuk menunjang pelaksanaan program pendidikan, apalagi disaat perkembangan produk teknologi komunikasi yang semakin canggih, menuntut pengetahuan dan keterampilan serta kecakapan yang memadai dari para guru dan pelaksana program pendidikan lainnya.

Pendidikan dan kurikulum harus mampu merespon perkembangan Ilmu Pengetahuan dan Teknologi yang begitu cepat, karena pendidikan merupakan upaya menyiapkan peserta didik menghadapi masa depan yang lebih baik. Pengembangan kurikulum semua mata pelajaran termasuk di dalamnya Pendidikan Agama Islam haruslah berlandaskan pada perkembangan ilmu pengetahuan dan teknologi. Perkembangan ilmu pengetahuan dan teknologi secara langsung berimplikasi terhadap pengembangan 
kurikulum yang di dalamnya mencakup pengembangan isi/materi pendidikan, penggunaan strategi dan media pembelajaran, serta penggunaan sistem evaluasi.

Dalam tulisan ini penulis mencoba menguraikan bagaimana teknologi menjadi landasan dalam pengembangan kurikulum khususnya Pendidikan Agama Islam (PAI).

\section{B. Bahasan Utama}

\section{Pengertian Teknologi}

Dari para ahli, kita sering mendengar pernyataan bahwa ilmu bukan hanya untuk ilmu. Hal ini berarti, perkembangan ilmu pengetahuan diharapkan dapat memberikan sumbangan kepada bidang-bidang kehidupan atau ilmu yang lainnya. Sumbangan yang berupa penggunaan atau penerapan suatu bidang ilmu pengetahuan terhadap bidang-bidang lain disebut teknologi seperti yang dinyatakan oleh Kast dan Rosenweig (1962, hal. 11)

\section{Technology is the art of utilizing scientific knowledge.}

Iskandar Alisyahbana (1980: 1) merumuskan lebih lengkap dan jelas tentang teknologi, yaitu cara melakukan sesuatu untuk memenuhi kebutuhan manusia dengan bantuan alat dan akal (hardware dan software) sehingga seakan-akan memperpanjang, memperkuat, atau membuat lebih ampuh anggota tubuh, pancaindra, dan otak manusia.

Teknologi menurut Wikipedia adalah keseluruhan sarana untuk menyediakan barang-barang yang diperlukan bagi kelangsungan dan kenyamanan hidup manusia. Harahap, Poerbahawadja, 1982 : 1357) mengatakan teknologi adalah:1) Ilmu yang menyelidiki cara- cara kerja di dalam tehnik, 2) Ilmu pengetahuan yang digunakan dalam pabrik- pabrik dan industri- industri.

Perkembangan yang begitu cepat pada beberapa dekade terakhir adalah perkembangan teknologi transportasi, komunikasi, dan informatika, serta media cetak. Perkembangan teknologi terbesar dalam pertengahan abad ke-20 berkenaan dengan penjelajahan luar angkasa. Temuan-temuan dibidang fisika, kimia, dan matematika mengembangkan teknologi ruang angkasa dan kemiliteran.

Kemajuan cepat dunia dalam bidang informasi dan teknologi dalam dua dasa warsa terakhir telah berpengaruh pada peradaban manusia melebihi jangkauan pemikiran manusia sebelumnya. Pengaruh ini terlihat pada pergeseran tatanan sosial, ekonomi dan politik yang memerlukan keseimbangan baru antara nilai-nilai, pemikiran dan cara-cara kehidupan yang berlaku pada konteks global dan lokal. Selain itu, dalam abad pengetahuan sekarang ini, diperlukan masyarakat yang berpengetahuan melalui belajar sepanjang hayat 
dengan standar mutu yang tinggi. Sifat pengetahuan dan keterampilan yang harus dikuasai masyarakat sangat beragam dan canggih, sehingga diperlukan kurikulum yang disertai dengan kemampuan meta-kognisi dan kompetensi untuk berfikir dan belajar bagaimana belajar (learning to learn) dalam mengakses, memilih dan menilai pengetahuan, serta mengatasi siatuasi yang ambigu dan antisipatif terhadap ketidakpastian.

\section{Peranan Ilmu Pengetahuan dan Teknologi dalam Pendidikan}

Pendidikan adalah usaha sadar untuk menyiapkan peserta didik melalui kegiatan bimbingan, pengajaran dan atau latihan, serta membekali anak didik dengan ilmu pengetahuan guna perannya di masa datang. Sementara itu teknologi adalah aplikasi dari ilmu pengetahuan ilmiah dan ilmu-ilmu lainnya untuk memecahkan masalah-maslaah praktis. Dengan demikian Ilmu dan teknologi tidak bisa dipisahkan. Ilmu pengetahuan dan teknologi berkembang teramat pesat seiring lajunya perkembangan masyarakat.

Pendidikan mendapat pengaruh yang cukup besar dari ilmu dan teknologi. Pendidikan sangat erat hubungannya dengan kehidupan sosial, sebab pendidikan merupakan salah satu aspek sosial. Pendidikan tidak terbatas pada pendidikan formal saja, melainkan juga pendidikan nonformal. Sebab pendidikan meliputi segala usaha sendiri atau usaha pihak luar untuk meningkatkan pengetahuan dan kecakapan, memperoleh keterampilan, dan membentuk sikap-sikap tertentu. (Sukmadinata, 2011:75)

Perkembangan iptek, baik secara langsung maupun tidak langsung menuntut perkembangan pendidikan. Pengaruh langsung perkembangan ilmu pengetahuan dan teknologi adalah memberikan isi atau materi atau bahan yang akan disampaikan dalam pendidikan.

Pengaruh tak langsung adalah perkembangan ilmu pengetahuan dan teknolgi menyebabkan perkembangan masyarakat, dan perkembangan masyarakat menimbulkan problem baru yang menuntut pemecahan dengan pengetahuan, kemampuan, keterampilan baru yang dikembangkan dalam pendidikan. Oleh karena itu, kurikulum seyogyanya dapat mengakomodir dan mengantisipasi laju perkembangan ilmu pengetahuan dan teknologi, sehingga peserta didik dapat mengimbangi dan sekaligus mengembangkan ilmu pengetahuan dan teknologi untuk kemaslahatan dan kelangsungan hidup manusia.

Kemajuan ilmu pengetahuan dan teknologi membawa manusia pada masa yang berbeda dengan masa sebelumnya, bahkan masa yang tidak pernah terbayangkan di masa lalu. Munculnya hasil-hasil teknologi seperti hasil teknologi transportasi, yang bukan 
hanya menyebabkan manusia bisa menjelajah dunia, bahkan hingga luar angkasa. Demikian juga kemajuan dalam teknologi informasi dan komunikasi, yang memungkinkan manusia untuk mengetahui informasi dari berbagai belahan dunia dalam waktu singkat.

Namun demikian, kemajuan tersebut tidak hanya memunculkan dampak positif, bersamaan dengan itu muncul pula berbagai dampak negatif kemajuan teknologi yang sering membuat cemas. Kemajuan transportasi, khususnya bertambahnya kendaraan di kota-kota besar dengan jumlah yang begitu besar, sering menimbulakn kemacetan, karena tidak dibarengi dengan sarana jalan yang memadai, timbulnya banyak kecelakaan karena kelalaian pengendara dsb. Hasil teknologi informasi yang pada saat ini membuat cemas seluruh masyarakat, dengan fasilitasnya, yang memudahkan bagi pemakai, tidak terlepas anak-anak, untuk mengakses pornografi, kekerasan dsb, yang menyebabkan gesekan nilainilai, norma, dan budaya.

Munculnya permasalahan-permasalahan tersebut menyebabkan tugas-tugas pendidikan yang diimplementasikan dalam kurikulum menjadi kian kompleks. Tugas sekolah menjadi semakin berat, dan kadang-kadang tidak mampu lagi melaksanakan semua tuntutan masyarakat. Bahkan seiring dengan kemajuan zaman, tugas-tugas yang dahulu bukan menjadi tanggung jawab sekolah kini menjadi tugas sekolah. Sekolah tidak hanya bertugas menanamkan dan mewariskan ilmu pengetahuan, tetapi juga harus memberi keterampilan, juga harus menanamkan budi pekerti dan nilai-nilai.

Dengan tugas dan tanggungjawab pendidikan yang demikian berat, kurikulum sebagai alat pendidikan, harus selalu diperbarui menyesuaikan dengan perubahan yang terjadi baik isi maupun prosesnya, mengikuti perkembangan ilmu pengetahuan dan teknologi yang demikian cepat. Hal penting yang perlu diperhatikan dan diantisipasi oleh para pengembang kurikulum seperti yang dikatakan Sanjaya (2008: 58-61) adalah:

\section{a. Perubahan Pola Hidup}

Kemajuan di bidang teknologi memiliki andil besar dalam perubahan pola hidup. Penggunaan pesawat telepon yang lebih memudahkan untuk berkomunikasi, munculnya stasiun-stasiun TV yang menawarkan berbagai acara selama dua puluh empat jam dari mulai bidang pendidikan, informasi sampai hiburan dengan berbagai macam variasinya, tekhnologi dalam bidang kesehatan dan lain sebagainya, merupakan faktor yang mendorong terjadinya perubahan pola hidup dan bahkan tatanan sosial masyarakat. 
Pola kehidupan masyarakat industri modern menurut Sanjaya $(2008,58)$ memiliki karakteristik yang berbeda dengan pola kehidupan agraris. Perbedaan tersebut dapat dilikhat:

1. Dari pola kerja. Pada masyarakat agraris pola kerja sangat teratur yang berlangsung siang hari pada waktu yang tetap. Tidak demikian halnya pada masyarakat industri, selain masyarakat menggunakan waktu yang cukup panjang untuk bekerja juga memiliki pola yang tidak beraturan. Kenyataan seperti ini memiliki konsekwensi terhadap cara dan strategi yang harus dipersiapkan oleh lembaga pendidikan. Kurikulum harus di desain agar mampu membentuk manusia produktif yang bukan hanya dapat bekerja, akan tetapi lebih jauh dapat mencintai pekerjaan.

2. Pola hidup yang sangat tergantung pada hasil-hasil tekhnologi. Pada masyarakat industri banyak sekali jenis-jenis pekerjaan yang sangat menggantungkan tekhnologi, dari mulai pekerjaan ibu-ibu rumah tangga sampai pada pekerjaanpekerjaan kantor. Keahlian tersebut tentu saja harus dipersiapkan oleh lembaga pendidikan.

3. Pola hidup dalam sistem perekonomian baru. Perubahan pola hidup ini ditandai dengan penggunaan produk jasa perbankan dan asuransi untuk kegiatan perekonomian, seperti menabung, perkreditan dan permodalan usaha. Demikian juga tumbuh suburnya pusat-pusat perbelanjaan dalam gedung bertingkat menggantikan pasar-pasar tradisional.

b. Perubahan Kehidupan sosial politik

Arus globalisasi yang bergerak sangat cepat membawa perubahan kehidupan sosial politik ke seluruh penjuru dunia tak terkecuali ke dalam kehidupan sosial politik.Di Indonesia perubahan tersebut adalah ditandai dengan munculnya gerakan reformasi yang menjatuhkan rezim orde baru selama 32 tahun.

Dengan munculnya era reformasi, semuanya mestinya berubah. Pendidikan harus diarahkan untuk menciptakan manusia-manusia yang kritis dan demokratis. Untuk itu perubahan ke arah transparansi harus ditangkap secara utuh oleh para pengembang kurikulum. Kehidupan yang demokratis harus menjiwai isi kurikulum.

Sehubungan dengan hal di atas, maka para pengembang kurikulum dalam melaksanakan tugasnya harus melakukan hal-hal sebagai berikut: 
a. Mempelajari dan memahami kebutuhan masyarakat seperti yang dirumuskan dalam Undang-undang, keputusan pemerintah, peraturan daerah dan alin sebaginya.

b. Menganalisis budaya masyarakat tempat sekolah berada.

c. Menganalisis kekuatan serta potensi-potensi daerah

d. Menganalisis syarat dan tuntutan tenaga kerja

e. Menginterpretasikan kebutuhan individu dalam kerangka kepentingan masyarakat.

Pengembangan kurikulum adalah proses perencanaan dan penyusunan kurikulum oleh pengembang kurikulum (curriculum developer) dan kegiatan yang dilakukan agar kurikulum yang dihasilkan dapat menjadi bahan ajar dan acuan yang digunakan untuk mencapai tujuan pendidikan nasional. Pengembangan kurikulum menunjuk pada kegiatan menghasilkan kurikulum. Kegiatan pengembangan, terdiri dari kegiatan penyusunan, pelaksanaan, penilaian, dan penyempurnaan sehingga menghasilkan sesuatu (Saridudin, 2020). Pengembangan kurikulum berorientasi teknologi ini menjadi kebutuhan yang tidak bisa ditunda-tunda lagi untuk dipraktikkan di lembaga pendidikan dasar dan menengah sekrang ini untuk menjawab berbagai kebutuhan siswa di masyarakat.

\section{Teknologi dan Transformasi Kurikulum Pendidikan Dasar dan Menengah}

Kita harus melihat bagaimana tehnologi mempengaruhi Sekolah-sekolah di seantero dunia termasuk di Indonesia. Menjamurnya HP dan digital music player di kalangan siswa SD/MI, SMP/MTs., SMA/MA dan SMK menunjukkan bahwa tekhnologi telah merubah kehidupan mereka dalam beberapa tahun terakhir ini. HP sekarang adalah fashion accesories yang secara praktis dimiliki oleh setiap orang, dan MP3 music player seperti iPod ada dimana-mana. Siswa dapat terlihat membawa iPods, HP, video cameras, laptop dan kamera digital kemanapun mereka pergi. Websites seperti facebook dan MySpace merubah cara mereka berkomunikasi dan bersosialisasi baik di sekolah, di rumah di kampus atau di tempat lain. Konten media masuk ke sekolah setiap menit melalui HP, internet, email, sms dan entertaimen yang umum (musik, video, blog,dll).

Untuk bersaing dengan media dan lingkungan teknologi yang berkembang di masyarakat, Parkay, Hass and Anctil $(2010,320)$ mengatakan "educators must incorporate technology into the modern curriculum". Mereka dengan mengutip pernyataan Prensky mengatakan "menolak teknologi digital saat ini akan benar-benar mematikan pendidikan anak-anak. Mereka hidup dalam dunia yang berbeda dan menuntut sesuatu yang lebih cepat dari pada apa yang disampaikan dan dipresentasikan oleh guru. 
Menurut editor journal Technological Horizons in Education (T.H.E) dalam Parkay, Hass and Anctil (2010: 321), tekhnologi harus direfleksikan dalam proses pengembangan kurikulum. Dalam journal itu dikatakan "We need to bring our curriculum up to 21 st century reality. We need to access our student's knowledge and skill and way that is consistent with how that knowledge and those skill are used in the real world. This is the context in which we should be integrating technology throughout all of curriculum and instruction”.

Untuk menciptakan leadership Pengembangan Kurikulum yang efektif, para pemimpin sekolah harus mengerti dan menguasai teknologi. Di masa lalu, siswa pergi ke sekolah dengan membawa buku catatan, pensil, dan pena; Di masa sekarang anak-anak datang ke sekolah dengan membawa HP, Laptop, dan iPod. Di era digital sekarang ini media elektronik tumbuh dengan menggiurkan, mempengaruhi dan menjalar ke berbagai aspek.

Bill Gates yang dikutif Parkay, Hass and Anctil (2010, 322) dalam tulisannya Vision 2020: Transforming Education and Training through Advanced Technology mendeskripsikan pengaruh technologi pada kurikulum "The internet has brought an unprecedented level of great educational content to wide audience, encouraging teacher to share curriculum and resourches worldwide. E-mail has facilitated improved communication among administrator, teachers, students, parents and educational researches, and emerging Web services technologies will create further opportunities for collaborative learning. Increased industry ang goverment funding in learning science promises to vastly improve the ways technology is applied to learning. And in the years ahead, a whole generation of kids will leave college and enter the workforce with the broad understanding of the ways they can use technology effectively in their jobs.

Banyak departemen pendidikan di berbagai negara telah mengembangkan panduan kompetensi teknologi yang dapat digunakan para curriculum leader dalam mendesain program pengembangan staff untuk para guru.

Sejak awal 1980 an para curriculum leader telah menggunakan komputer sebagai sistem penyampaian pengajaran dalam mempresentasikan informasi pada siswa. Mereka memasukkan teknologi terkini untuk menstimulasi pemikiran yang lebih tinggi, kreativitas, dan pemecahan masalah. Curriculum leader faham bahwa teknologi adalah alat untuk menciptakan kekayaan, menstimulasi lingkungan yang memelihara kolaborasi, inqury dan membuat keputusan. 
Tekhnologi telah mentransformasi pengajaran dan pembelajaran di sekolah. Setiap hari para siswa berkomunkasi melalui internet dengan siswa yang lain di seluruh dunia. Pengaruh tekhnologi terhadap kurikulum seperti yang dikatakan Bill Gate dalam Parkay, Hass and Anctil $(2010,322)$ : In the next view years-a time I call the Digital decade-we'll see computing become a much more significan and indispensable part of all our lives".

The CEO Forum on Education and Technology (2001) yang dikutif Parkay, Hass and Anctil (2010, 323) menekankan bahwa guru harus menggunakan teknologi untuk membantu siswa dalam mengembangkan "21st century skills”, yaitu :

a. Digital Age Literacy, mencakup :

1. Basic, scientific and technological literacy

2. Visual and information literacy

3. Cultural literacy and global awareness

b. Inventive Thinking, mencakup :

1. Adaptability/managing complexity

2. Curiosity, creativity, and risk taking

3. High order thinking and sound reasoning

c. Effective communication, mencakup :

1. Teaming, collaboration, and interpersonal skill

2. Personal and social responsibility

3. Interactive communication

d. High Productivity, mencakup :

1. Prioritizing, planing and managing for results

2. Effective use of real world tools

3. Relevant, high-quality products

Ted McCain dan Ian Juke (2001) memprediksikan bahwa teknologi di masa depan untuk bidang elektronika akan tumbuh dengan pesat 1.000 .000 kali lebih cepat sejak perkembangan ENIRC (Electronic Numerical Integrator and Calculator) yang merupakan komputer pertama yang diperkenalkan 1946. Seberapa banyak dan seberapa cepat informasi dapat diproses, teknologi dengan sendirinya akan merubah hakikat persekolahan dan kelas dengan sendirinya. Di kelas di masa depan akan kelihatan sangat berbeda dengan kelas yang ada sekarang ini.

Karena keterampilan tekhnologi dibutuhkan di tempat kerja, maka derajat melek tekhnologi yang tinggi dibutuhkan dalam pengembangan kurikulum, implementasi dan 
evaluasi. Jadi kecakapan dalam bidang tekhnologi harus menjadi bagian yang penting dalam pengembangan leader kurikulum profesional. Para pengembang kurikulum sekarang ini bersama-sama dengan orang yang tertarik pada dunia pendidikan akan menjadi lebih rumit dalam memahami kekuatan dan keterbatasan tekhnologi sebagai alat untuk mempertinggi kurikulum.

\section{Landasan Ilmu Pengetahuan dan Teknologi dalam Pengembangan Kurikulum Pendidikan Agama Islam (PAI)}

Pendidikan Agama Islam adalah segenap kegiatan yang dilakukan seseorang untuk membantu seorang atau sekelompok peserta didik dalam menanamkan dan menumbuhkembangkan ajaran Islam dan nilai-nilainya untuk dijadikan sebagai pandangan hidupnya, yang diwujudkan dalam sikap hidup dan dikembangkan dalam keterampilan hidupnya sehari-hari (Saridudin, 2021).

Keterampilan abad 21 seperti yang dijelaskan Parkay, Hass and Anctil di atas untuk saat ini perlu dikembangkan dalam pengembangan kurikulum Pendidikan Agama Islam. Peserta didik perlu dibekali dengan kemempuan teknologi agar mereka siap menghadapi tantangan global, modernisasi, globalisasi dan khususnya dalam menghadapi duna kerja. Kurikulum Pendidikan Agama Islam jangan hanya berurusan dengan masalah-masalah akhirat atau ukrawi saja, tetapi bersentuhan dengan kepentingan peserta didik di dunia. Pendidikan Agama Islam harus bersentuhan dengan dunia teknologi agar materi yang dikembangkan tidak ketinggalan zaman (out of date).

Guru PAI sebagai pemegang kendali utama dalam pembelajaran Pendidikan Agama Islam dituntut untuk menguasai teknologi, ia harus berupaya agar kehadiran Agama Islam di tengah masyarakat selalu dirindukan dan dibutuhkan oleh peserta didik. Guru PAI harus bisa mengkontekstualiasai ajaran agama dengan kehidupan dunia nyata peserta didik, sehingga materi-materi Pendidikan Agama Islam selalu aktual dengan kehidupan dunia nyata mereka.

Metode pembelajaran Agama Islam sebagai dampak dari perkembangan teknologi informasi dan komunikasi tidak hanya terfokus pada metode ceramah yang teachercentered, tetapi siswa diberi kesempatan untuk berdialektika dengan teknologi. Siswa diberi kesempatan untuk mencari materi yang diajarkan dari internet, web, e-book, facebook, email, sms atau yang lainnya. Sehingga pembelajaran yang disampaikan oleh 
guru tidak menjenuhkan bagi peserta didik, dan peserta didik merasa bahwa belajar Agama merupakan kebutuhan pokok yang tidak bisa ditinggalkan.

Pembelajaran Pendidikan Agama Islam yang dilandasi nilai-nilai teknologi diharapkan menjadi media dalam pengembangan pendidikan Karakter. Pengembangan pendidikan karakter dalam pembelajran PAI di sekolah/madrasah meliputi pengembangan 17 karakter utama, yaitu: kereligiusan, kejujuran, kecerdasan, ketangguhan, tanggung jawab, kepedulian, kedemokratisan, kesantunan, kedisiplinan, cinta ilmu, keingintahuan, percaya diri, menghargai keberagaman, kepatuhan terhadap aturan sosial, gaya hidup sehat, kesadaran akan hak dan kewajiban, dan kerja keras. Dari 17 nilai itu ada 6 nilai karakter pokok yang menjadi pangkal tolak pengembangan karakter pada Sekolah menengah, yaitu kereligiusan, kejujuran, kecerdasan, ketangguhan, kedemokratisan, dan kepedulian (Saridudin, 2021). Nilai-nilai karakter ini yang harus dikuatkan oleh guru dalam setiap pembelajaran, sehingga hal tersebut bisa menjadi bekal ketika siswa menjalani kehidupan di masyarakat.

\section{Penutup}

Ilmu pengetahuan dan teknologi mempunyai hubungan timbal-balik dengan pendidikan dan kurikulum. Pendidikan dan kurikulum harus mampu merespon perkembangan Ilmu Pengetahuan dan Teknologi yang begitu cepat, karena pendidikan merupakan upaya menyiapkan peserta didik menghadapi masa depan yang lebih baik. Pengembangan kurikulum semua mata pelajaran termasuk di dalamnya Pendidikan Agama Islam haruslah berlandaskan pada perkembangan ilmu pengetahuan dan teknologi. Perkembangan ilmu pengetahuan dan teknologi secara langsung berimplikasi terhadap pengembangan kurikulum yang di dalamnya mencakup tujuan, materi, metode dan evaluasi. Teknologi memiliki peranan penting dalam pengembangan kurikulum Pendidikan Agama Islam karena materi PAI harus selalu up to date dengan kondisi dan kebutuhan peserta didik. Pembelajaran Pendidikan Agama Islam harus selalu kontekstual dengan kehidupan nyata peserta didik agar keberadaannya selalu hadir dan menjadi kebutuhan peserta didik.

\section{References}

Hamalik, Oemar (2008). Dasar - Dasar Pengembangan Kurikulum, Bandung: PT. Remaja Rosda Karya 
Parkay, Hass, Anctil, (2010). Curriculum Leadership: Reading for Developing Quality Educational Programs. USA: Perason Education

Saridudin. (2021). Pengembangan Pendidikan Karakter Dalam Pembelajaran PAI Pada Sekolah Menengah. OSF Preprints, 1. https://doi.org/10.31219/osf.io/7p54a

Saridudin, S. (2020). Pengembangan Kurikulum Pendidikan Diniyah Formal (PDF) Di Pesantren Ulya Zainul Hasan Probolinggo. EDUKASI: Jurnal Penelitian Pendidikan Agama Dan Keagamaan, 18(1), 84-99. http://dx.doi.org/10.32729/edukasi.v18i1.690

Sanjaya, Wina (2011), Kurikulum dan Pembelajaran, Jakarta : Prenada Media Grup

Sukmadinata, Nana S (2011), Pengembangan Kurikulum Teori dan Praktik, Bandung : PT. Remaja Rosda Karya

Tim Pengembang MKDP Kurikulum dan Pembelajaran Jurusan Kurikulum dan Teknologi Pendidikan Fak. Ilmu Pendidikan UPI. (2011). Kurikulum dan Pembelajaran. Jakarta: PT Rajagrafindo Persada. 